\title{
Canadian clinical genetics marks a milestone
}

$\mathrm{L}$ ike early explorers who claimed an uninhabited land mass by planting a flag, many pioneering biotechnology firms acquired patents on genes simply by "discovering" these naturally occurring sequences. This legal control mattered little when the biomolecular tools for extracting information from these genes were cumbersome and expensive. But those days are fading fast. Clinicians conducting genetic tests can now analyze all or most of a human being's 23000 genes with a single in-house procedure that can reveal if a patient's condition is linked to one gene.

Now the legal legacy of gene patenting prevents clinicians from making full use of this technology. That was the conundrum faced by Chief Geneticist Dr. Gail Graham and colleagues at the Children's Hospital of Eastern Ontario (CHEO) in Ottawa. The institution conducts cardiac genetic tests that should include a set of genes associated with Long QT syndrome, a potentially fatal heart disorder. However, these genes were patented in the United States by Nebraska-based Transgenomic Inc.

"In theory, the patent said you are not allowed to read through these genes and detect mutations," says Graham.

Previously, CHEO sent samples to labs in the US to conduct Long QT tests, a process that introduced delays and increased costs. But Graham and others lobbied CHEO administrators to mount a legal challenge to the Transgenomic patent. They argued that human genes should not be subject to patents for commercial or any other purposes. The legal wrangling began in late 2014, when CHEO initiated the case with a federal court and wound up with the milestone Public Health Access Agreement on Mar. 9.

In essence, Transgenomic granted CHEO and other public-sector Canadian hospitals and labs the right to conduct Long QT tests without paying any kind of fee or royalty. The settlement specifically upholds the patent, however, stating that the company "reserves all rights to use, commercialize, license, and otherwise exploit all aspects of the Long QT Patents for any use or purpose."

Nevertheless, this outcome could serve as a precedent for overriding similar restrictions on other patented genes.

Identifying those patents will take time and expertise, but the need to do so is urgent, says Nathaniel Lipkus, an intellectual property lawyer with Toronto-based Osler, Hoskin \& Harcourt LLP, who took up CHEO's case pro bono. He says technology is moving far faster than the law, as evidenced by the fact that CHEO's genomic testing regime has become far more comprehensive in the two years since he took on the case.

"I never would have imagined that the hospital would be looking to deploy a 5000-gene test before we finished the case," he says. "That's the reality."

The agreement shows how the importance of gene patents has effectively been undermined by the rapidly growing social value of acquiring much more diverse analytic information that can be derived from genes, says McGill University law professor Richard Gold.

"The action is no longer about finding genes - that's old hat," says Gold. The case removes a roadblock that was facing every medical centre with a stake in genetic testing, he adds. "If anything, it should open up innovation in the field because the future is with large-scale testing and the analytics that go with it."

Above all, he salutes the administrative fortitude mustered by CHEO as a public institution that took on a legal risk. The result is a medical landscape in Canada that should never again include cease-and-desist letters from the holders of gene patents.

"My feeling is there'll just be resounding silence," he says, "and it's a silence that indicates we won." Tim Lougheed, Kingston, Ont.

CMAJ 2016. DOI:10.1503/cmaj.109-5259 